\title{
The Effect of Urinary Incontinence on Quality of Life of Women at Childbearing Age in Jeddah, Saudi Arabia
}

\author{
Marwan A. Bakarman ${ }^{1}$ \& Sadiah Saeed Al-Ghamdi ${ }^{2}$ \\ ${ }^{1}$ Rabigh Medical College, King Abdulaziz University, Jeddah, KSA \\ ${ }^{2}$ Minisrty of Health, Primary Health Care, Jeddah, KSA \\ Correspondence: Marwan A.Bakarman, Rabigh Faculty of Medicine, King Abdulaziz University, KSA. Tel: \\ 966-553-370-470. E-mail: mbakarman@kau.edu.sa
}

Received: March 24, 2015 Accepted: July 6, 2015 Online Published: July 20, 2015

doi:10.5539/gjhs.v8n2p281 URL: http://dx.doi.org/10.5539/gjhs.v8n2p281

\begin{abstract}
To estimate the prevalence of urinary incontinence among women of childbearing age at Maternity and Children's Hospital (MCH), Jeddah, 2012, and to assess its impact on the quality of their life. A cross- sectional analytic approach was carried out among women of childbearing age seen at MCH, Jeddah. Systematic random sampling technique was followed. Each woman fulfilling the inclusion criteria was invited to enroled in the study, the inclusion criteria were women aged 15-50 years, agreed to participate in the study, the exclusion criteria were pregnant women and patients who are seriously ill. Self-administered questionnaire using the King's Health Questionnaire was utilized to measure Health Related Quality of Life (HRQOL) of patients with UI. Out of 1200 patients attending the gynecology clinic in the $\mathrm{MCH}, 412(34.3 \%)$ were diagnosed as having UI. Their age ranged between 15 and 50 years with a mean of $34.3 \pm 7.2$ years. Almost $50 \%$ indicated that UI affected them badly as wife, mother, their emotions, and their physical and social activities. The most commonly occurring problems were frequent micturition $(88.3 \%)$, nocturnal enuresis $(87.9 \%)$. The least occurring, were kidney problems (38.6\%) and dripping during sexual activities (40.8\%). Increasing age and higher parity were significantly associated with limitations in different life domains. Urinary incontinence is common and often disturbing for Saudi women. It adversely impaired their quality of life.
\end{abstract}

Keywords: urine incontinence, quality of life, Saudi women, childbearing age

\section{Introduction}

The definition of urinary incontinence (UI) is the complaint of involuntary loss of urine (Hylen, 2010). Urinary incontinence can be classified as: Stress incontinence which is the involuntary loss of urine on exertion or effort, sneezing, or coughing, Urgency incontinence is the involuntary loss of urine accompanied by or immediately preceded by urgency (Hylen, 2010). Mixed incontinence is the involuntary loss of urine associated with urgency and with effort, exertion, coughing or sneezing (Faltin, 2008). Urinary incontinence was experienced by more than $30 \%$ of adult women, and Stress urinary incontinence alone accounts for up to half of all cases; generally the prevalence of UI considered to be from $20 \%$ to $50 \%$ with the peak to be in the childbearing age group (up to $40 \%$ ) and then the prevalence increasing in elderly to reach to 50\%. In Saudi Arabia a local study done in 2008 at a primary care center in Jeddah found that the prevalence of UI was $41.4 \%$ (Brasha, 2008). This local research studied the prevalence of UI, the risk factors and the barriers to seek health advices but not relating UI to quality of life.

Urinary incontenance remains a silent problem as a significant number of women do not seek treatment, even when their symptoms cause major distress and hinder their daily activities (Riss \& Kargl, 2011). While incontinence does not lead to death, it can have a profound effect on quality of life comparable to that of stroke, arthritis and chronic-obstructive pulmonary disease. In addition, incontinence accounts for more than $\$ 20$ billion in annual expenditures in the United States, an amount greater than the annual direct cost of breast, ovarian, cervical, and uterine cancers (Barber et al., 2005).

One of the major risk factors for stress incontinence is vaginal child birth, it was reported that one third of female experienced stress incontinence 5 years after their first vaginal delivery (Riss \& Kargl, 2011).

The term Quality of life is used generally to indicate 'happiness', but for every patient it may have different 
meaning: high income and money, good family life and relationship with others, job satisfaction, good physical and mental health (Falten, 2008).

Urinary incontinence can affect the patient's life in many ways, some women miss the ability to practice their favorite sports, some are bothered by having to wear sanitary protection, and others their sex life and intimate relationship are much affected by the negative impact of urinary incontinence (Senra, 2015; Babic, 2015).

Although it is still important to do researches in the diagnostic procedure of urinary incontinence, nowadays the focus of new researches has been shifted from only describing and evaluating the phenomenon of urinary incontinence to ask more details regarding the different kinds of urinary incontinence and how it affects the quality of life of a woman (Frick et al., 2009). Therefore our objectives in this study were to estimate the prevalence and assess the impact of different clinical types of incontinence on quality of life among women of childbearing age at Maternity and Children's Hospital, Jeddah, Saudi Arabia, 2012. We expected that exploring quality of life of those women helps us to better understand what our patients feel and what their real needs and to draw the attention of family physicians to the importance of identifying the population at risk in an attempt for early diagnosis and proper intervention

\section{Methodology}

\subsection{Research Desigin and Subjects}

This cross-sectional analytic study done in the Maternity and Children's Hospital (MCH), which is the biggest hospital in Jeddah City in Saudi Arabia (SA). There are approximately 44,703 patients attending the Gynecology clinics and about 6,695 patients for Obstetric clinics yearly.

The total monthly number of patients attending the Gynecology clinics was estimated to be roughly $\pm 4,000$ patients, and we selected $30 \%$ of this number as a sample size for our study which was equal to 1,200 patients.

\subsection{Sampling}

Systematic random sampling technique was followed (every third patient was selected). Each assigned woman aged 15-50 years old, Saudi and non-Saudi and agree to participate in the study was invited to be enrolled in the study after describing the aim of the study for her. The exclusion criteria were pregnant women and patients who are seriously ill. Those who agreed were requested to fill the Self-administered questionnaire.

\subsection{Reseacrch Insturment}

Those who agreed were requested to fill the Self-administered questionnaire. The Kings Health Questionnaire is a disease specific health related quality of life (HRQOL) instrument to measure quality of life in patients with urinary incontinence (El-Azab, Mohammed \& Sabra, 2007). . It is used in many clinical studies and was proven to be valid and reliable (Brasha, 2008). It was translated into Arabic then again translated into English to ensure lexical equivalence.

\subsection{Data Analysis}

Data entry and statistical analyses were done using statistical software package SPSS 16.0.

\section{Results}

Out of the 1,200 patients, there were $412(34.3 \%)$ diagnosed as having urinary incontinence. Table (1) demonstrates that $14.6 \%$ of the patients indicated that they are complaining of chronic diseases e.g. diabetes, hypertension and bronchial asthma. $10.9 \%$ of the patients pointed out that they had previous surgical operations in the pelvis not including caesarean sections (CSs). Meanwhile, it was found that $105(25.5 \%)$ of the patients had previous sections, out of them there were $13.6 \%$ who had two or more CSs. Only 22(5.3\%) of the patients were current smokers.

Table (2) demonstrates that, in general, almost one half of the patients indicated that urine incontinence affects badly their role, physical and social activities and their emotions. The effect was remarkable on job and daily outdoor activities, where $20.2 \%$ of the patients expressed that they were moderately or a lot affected. This was followed by the effect on ability to travel where the equivalent percentage accounted for $16.5 \%$. Considering the effect on emotions, it was realized that $19.7 \%$ of the patients confessed that they are moderately or a lot of time feeling anxious or nervous.

On the other hand, a higher proportion of the patients (almost two thirds) reported that urine incontinence affects their sleeping and energy; $12.3 \%$ patients pointed out that they were moderately or a lot of time having their sleep pattern affected and $16.1 \%$ were feeling tired and exhausted. Regarding effect of incontinence on personal relationships, only patients with whom the items were applicable, are displayed. It was noticed that sexual life 
was the most affected; where $52.9 \%$ of the patients indicated that they suffered in various degrees, out of them $18.7 \%$ reported moderate effect and $4 \%$ described the effect as being "a lot".

Table (3) illustrates that the most commonly occurring problems among the study group were frequently going to the WC $(88.3 \%)$ followed by getting up at night to pass urine and dripping associated with physical exercises (87.9\%); and the least to occur were the kidney problems (38.6\%) and dripping on sexual activities (40.8\%).

Table (4) describes the degree of limitations in different life domains calculated by summating sub items representing collectively each domain and presented in percentages. It was evident that the most affected domain was sleep and energy where the percentage of limitations reached $27.1 \%$ and the least affected was the social domain where the limitation accounted for $17.5 \%$.

From table (5), it is obvious that the percentages of limitations were higher among patients who reported that they are suffering from chronic diseases other than incontinence in all life domains. However, these differences were only statistically significant for the percentages of physical limitations $\mathrm{p}<0.05$.

Table 1. Relevant medical history of the patients $(n=412)$

\begin{tabular}{lll}
\hline & No. & $\%$ \\
\hline Chronic diseases & 60 & 14.6 \\
Yes & 352 & 85.4 \\
No & & \\
Previous surgical operation in the pelvis & 45 & 10.9 \\
Yes & 367 & 89.1 \\
No & & \\
Previous caesarean section & 307 & 74.5 \\
No & 105 & 25.5 \\
Yes & 49 & 11.9 \\
One caesarean section & 35 & 8.5 \\
$2-3$ caesarean section & 21 & 5.1 \\
$4+$ caesarean sections & & \\
Smoking status & 22 & 5.3 \\
Yes & 390 & 94.7 \\
No & & \\
\hline
\end{tabular}

Table 2. Effect of urine incontinence on different aspects of life and emotions of the patients

\begin{tabular}{|c|c|c|c|c|c|c|c|c|}
\hline & \multicolumn{8}{|c|}{ Response } \\
\hline & \multicolumn{2}{|c|}{ Not at all } & \multicolumn{2}{|c|}{ Slightly } & \multicolumn{2}{|c|}{ Moderately } & \multicolumn{2}{|c|}{ A lot } \\
\hline & No. & $\%$ & No. & $\%$ & No. & $\%$ & No. & $\%$ \\
\hline \multicolumn{9}{|l|}{ Role limitations } \\
\hline Affect household task & 217 & 52.7 & 152 & 36.9 & 37 & 9.0 & 6 & 1.5 \\
\hline $\begin{array}{l}\text { Affec job, or normal daily outdoor } \\
\text { activities }\end{array}$ & 222 & 53.9 & 107 & 26.0 & 70 & 17.0 & 13 & 3.2 \\
\hline \multicolumn{9}{|l|}{ Physical and social limitations } \\
\hline Affect physical activities & 201 & 48.8 & 153 & 37.1 & 54 & 13.1 & 4 & 1.0 \\
\hline Affect ability to travel & 231 & 56.1 & 113 & 27.4 & 59 & 14.3 & 9 & 2.2 \\
\hline Limit social life & 228 & 55.3 & 127 & 30.8 & 50 & 12.1 & 7 & 1.7 \\
\hline Limit ability to contact friends & 236 & 57.3 & 112 & 27.2 & 55 & 13.3 & 9 & 2.2 \\
\hline
\end{tabular}




\section{Emotion}

Feeling depressed

Feeling anxious or nervous

$\begin{array}{lll}215 & 52.2 & 147 \\ 219 & 53.2 & 112\end{array}$

35.7

45

10.9

5

1.2

Feeling bad about self

252

61.2

27.2

17.0

11

2.7

Sleep and energy

Affect sleep pattern

$\begin{array}{lll}137 & 33.3 & 224\end{array}$

26.0

40

9.7

13

3.2

Feeling tired and exhausted

$155 \quad 37.6$

191

$\begin{array}{ll}54.4 & 43 \\ 46.4 & 53\end{array}$

10.4

$\begin{array}{ll}8 & 1.9\end{array}$

Personal relationship

Affect relation with partner $(\mathrm{n}=216)$

Affect sex life $(\mathrm{n}=278)$

$\begin{array}{llllllll}117 & 54.2 & 76 & 35.2 & 21 & 9.7 & 2 & 0.9 \\ 131 & 47.1 & 84 & 30.2 & 52 & 18.7 & 11 & 4.0 \\ 124 & 57.4 & 63 & 29.2 & 22 & 10.2 & 7 & 3.2\end{array}$

Affect family life $(n=216)$

Table 3. Problems resulting from urine incontinence

\begin{tabular}{|c|c|c|c|c|c|c|}
\hline \multirow{3}{*}{ Problems } & \multicolumn{6}{|c|}{ Response } \\
\hline & \multicolumn{2}{|c|}{ Little } & \multicolumn{2}{|c|}{ Moderate } & \multicolumn{2}{|c|}{ A lot } \\
\hline & No. & $\%$ & No. & $\%$ & No. & $\%$ \\
\hline Frequent going to $\mathrm{WC}(\mathrm{n}=364 ; 88.3 \%)$ & 167 & 45.9 & 182 & 50.0 & 15 & 4.1 \\
\hline Getting up at night to pass urine $(\mathrm{n}=362 ; 87.9 \%)$ & 176 & 48.6 & 158 & 43.6 & 28 & 7.7 \\
\hline $\begin{array}{l}\text { Difficulty in controlling desire to urinate }(n=319 \text {; } \\
77.4 \%)\end{array}$ & 139 & 43.6 & 165 & 51.7 & 15 & 4.7 \\
\hline $\begin{array}{l}\text { Dripping accompanied by strong desire to urinate } \\
(\mathrm{n}=302 ; 73.3 \%)\end{array}$ & 149 & 49.3 & 139 & 46.0 & 14 & 4.6 \\
\hline $\begin{array}{l}\text { Dripping associated with physical exercise }(n=362 \text {; } \\
87.9 \%)\end{array}$ & 157 & 43.4 & 178 & 49.2 & 27 & 7.5 \\
\hline Nocturnal Enuresis $(n=224 ; 54.4 \%)$ & 150 & 67.0 & 65 & 29.0 & 9 & 4.0 \\
\hline Dripping on sexual activities $(n=168 ; 40.8 \%)$ & 94 & 56.0 & 43 & 25.6 & 31 & 18.5 \\
\hline Kidney problem $(\mathrm{n}=159 ; 38.6 \%)$ & 148 & 93.1 & 9 & 5.7 & 2 & 1.3 \\
\hline Pain in urinary bladder $(n=208 ; 50.5 \%)$ & 181 & 43.9 & 192 & 46.6 & 28 & 6.8 \\
\hline
\end{tabular}

Table 4. The mean percentages of limitations in different life domains resulting from urine incontinence

\begin{tabular}{lll}
\hline Different life domains & Mean percentage & SD \\
\hline Role limitations & 21.4 & 25.1 \\
Physical limitations & 21.5 & 23.9 \\
Social limitations & 17.5 & 22.9 \\
Personal relationships & 19.1 & 14.0 \\
Emotions & 20.6 & 24.1 \\
Sleep and energy & 27.1 & 22.8 \\
Severity measures & 23.1 & 19.4 \\
\hline
\end{tabular}


Table 5. Differences in the mean percentages of limitations in different life domains according to concurrent chronic diseases, rather than incontinence among the patients

\begin{tabular}{llll}
\hline \multirow{2}{*}{ Different life domains' limitations } & \multicolumn{2}{l}{ Concurrent chronic diseases } & \multirow{2}{*}{ P* } \\
\cline { 2 - 3 } & Yes & No & 0.053 \\
\hline Role limitation & $27.2 \pm 26.6$ & $20.5 \pm 24.7$ & 0.035 \\
Physical limitation & $27.5 \pm 25.8$ & $20.5 \pm 23.5$ & 0.480 \\
Social limitation & $19.4 \pm 26.6$ & $17.2 \pm 22.2$ & 0.552 \\
Personal limitation & $21.1 \pm 25.3$ & $18.7 \pm 23.8$ & 0.882 \\
Emotions & $20.0 \pm 20.8$ & $20.7 \pm 24.6$ & 0.715 \\
Sleep and energy & $26.1 \pm 23.2$ & $27.3 \pm 22.7$ & 0.178 \\
Severity measure & $26.3 \pm 21.1$ & $22.6 \pm 19.0$ & \\
\hline
\end{tabular}

* Based on independent sample t test.

\section{Discussion}

Urinary incontinence is not a life threatening disease, but usually accompanied by a negative impact on quality of life of the patient. UI has a physical and emotional affect, while at the same time it creates an additional financial burden.

Urinary Incontinence can seriously affect the social and personal life of patients, and ultimately their quality of life (Ghafouri, 2014; Minassian, 2015). Women with urine incontinence avoid social gatherings, as they are afraid that sudden loss of urine will put them in an embarrassing situation (Son, 2012).

In the present study, overall, there was a limitation in all domains of quality of life. The most affected domain was sleep and energy where the percentage of limitations reached $27.1 \%$ and the least affected was the social domain where the limitation accounted for $17.5 \%$. In Hong Kong Study (Pang 2005) impaired QOL, as assessed by IIQ-7, was reported at $11.7 \%$, while in Iran women with mixed incontinence reported significantly lower QOL and mental health $(\mathrm{P}<0.001)$ compared to those with stress and urge incontinence (Mallah, 2014).

We observed that almost half of the affected women found UI disturbing and claimed it had a detrimental effect on their daily functioning (household tasks and outdoor activities). In other studies, up to $60 \%$ of affected women were disturbed or worried by UI (Lopez, 2009; Guzeloy, 2014) and half of them went so far as to describe it as a moderate or even severe social handicap. However, in the present study, the percentage of affected women who sought medical attention was not included as in some cases, a few years pass before the patient brings the problem to the attention of her physician.

The tendency of affected women, especially in traditional Cultures as ours, to hide the problem raises the question of whether it is up to the family physician to broach the subject. Gynecologic consultations are the most frequent in the Saudi system, perhaps because women here have more direct access to female gynecologists, with no need for a referral from the family physician, but not to urologists. Experience has shown that even direct questioning of women about UI arouses very little response (Pakgohar, 2014). Specific attention, especially in high risk populations, needs to be addressed to the problem and new methods sought to highlight it. A good rapport between patient and physician, and patient trust in the physician may encourage more women to discuss the problem.

\section{Conclusions}

Urinary incontinence is common and often disturbing middle aged Saudi women, our study found that the prevalence was almosr $34 \%$. It adversely impaired their quality of life (QOL). Women`s age and parity were significantly related to impaired QOL.

\section{Acknowledgments}

Due thanks should be given to study participants for taking their time to complete the questionnaire. Also special thanks to Dr. Adel Ibrahim for his valuable review of statistical analysis and to Mrs. Bridget Somers for her valuable English editing. 


\section{References}

Anifantaki, S., Filiz, T. M., Alegakis, A., Topsever, P., Markaki, A., Cinar, N. D., ... Lionis, C. (2009). Does urinary incontinence affect quality of life of Greek women less severely? A cross-sectional study in two Mediterranean settings. Qual Life Res, 18, 1311-1319. http://dx.doi.org/10.1007/s11136-009-9545-4

Babic, U., Santric-Milicevic, M., Terzic, Z., Argirovic, A., Kojic, D., Stjepanovic, M., et al. (2015). Impact of Voiding and Incontinence Symptoms on Health-Related Life Quality in Serbian Male Population. Urol J, 12(3), 2196-203.

Barber, M. D., Mullen, K. J., Dowsett, S. A., \& Viktrup, L. (2005). The impact of stress urinary incontinence on sexual activity in women. Cleveland Clinic J Med, 72(3), 225-232. http://dx.doi.org/10.3949/ccjm.72.3.225

Brasha, H. (2008). Urinary incontinence among women: Prevalence, risk factors and barriers to health seeking in primary health care centers in Jeddah [dissertation]. Joint Program of Family \& Community Medicine, Jeddah.

Charalambous, S., \& Trantafylidis, A. (2009). Impact of urinary incontinence on quality of life. Pelviperineology, 28: $51-53$

Diniz, M. S., Feldner, P. C., Castro, R. A., Sartori, M. G., \& Girão, M. J. (2009). Impact of HTLV-I in quality of life and urogynecologic parameters of women with urinary incontinence. Eur J Obstet Gynecol Reprod Biol., 147(2), 230-3.

El-Azab, Mohammed, E. M., \& Sabra, H. I. (2007). The prevalence and risk factors of urinary incontinence and its influence on the quality of life among Egyptian women. Neurourology and Urodynamics, 26, 783-788. http://dx.doi.org/10.1002/nau.20412

Faltin, D. L. (2009). Epidemiology and definition of female urinary incontinence. J Gynecol Obstet Biol Repod., 38(8 Suppl), S146-52. http://dx.doi.org/10.1016/S0368-2315(09)73574-4

Frick, A. C., Huang, A. J., Van Den Eeden, S. K., Knight, S. K., Creasman, J. M., Yang, J., ... Brown, J. S. (2009). Mixed urinary incontinence: Greater impact on quality of life. J Urol., 182(2), 596-600. http://dx.doi.org/10. 1016/j.juro.2009.04.005

Ghafouri, A., Alnaimi, A. R., Alhothi, H. M., Alroubi, I., Alrayashi, M., Molhim, N. A., \& Shokeir, A. A. (2014). Urinary incontinence in Qatar: A study of the prevalence, risk factors and impact on quality of life. Arab $J$ Urol, 12(4), 269-74. http://dx.doi.org/10.1016/j.aju.2014.08.002

Guzeloy, M., Demirci, H., Coban, S., Belkiz, G. B., Ustunyurt, E., \& Isildak, S. (2014). Impact of urinary incontinence on quality of life among residents living in Turkey. Urol J, 11(2), 1447-51.

Haylen, B. T., de Ridder, D., Freeman, R. M., Swift, S. E., Berghmans, B., Lee, J., ... Schaer, S. N. (2010). An international urogynecological association (IUGA)/international continence society (ICS) joint report on the terminology for female pelvic floor dysfunction. Int Urogynecol J, 21, 5-26. http://dx.doi.org/10.1007/s 00192-009-0976-9

Kocak, I., Okyay, P., Dundar, M., Erol, H., \& Beser, E. (2005). Female urinary incontinence in the west of Turkey: Prevalence, risk factors and impact on quality of life. Eur Urology, 48, 634-641. http://dx.doi.org/ 10.1016/j.eururo.2005.04.017

Lasserre, A., Pelat, C., Gueroult, V., Hanslik, T., Chartier-Kastler, E., Blanchon, T., ... Bloch, J. (2009). Urinary incontinence in French women: Prevalence, risk factors and impact on quality of life. Eur Urol., 56, 177-183. http://dx.doi.org/10.1016/j.eururo.2009.04.006

Lopez, M., Ortiz, A. P., \& Vargas, R. (2009). Prevalence of urinary incontinence and its Association with Body Mass Index among Women in Puerto Rico. Journal of Women's Health, 18(10), 1607-1614. http://dx.doi. org/10.1089/jwh.2008.1207

Mallah, F., Montazeri, A., Ghanbari, Z., Tavoli, A., Haghollahi, F., \& Aziminekoo, E. (2014). Effect of Urinary Incontinence on Quality of Life among Iranian Women. J Family Reprod Health, 1, 13-19

Minassian, V. A., Sun, H., Yan, X. S., Clark, D. N., Stewart, W. F. (2015). The interaction of stress and urgency urinary incontinence and its effect on quality of life. Int Urogynecol J, 26(2), 269-76. http://dx.doi.org/10. 1007/s00192-014-2505-8

Pakgohar, M., Sabetghadam, S., Vasegh, S. F., \& Kazemnejad, A. (2014). Quality of life (QoL) and help-seeking in postmenopausal women with urinary incontinence (UI): A population based study. Arch Gerontol Geriatr, 
57(2), 403-7. http://dx.doi.org/10.1016/j.archger.2014.07.004

Pang, M. W., Leung, H. Y., Chan, L. W., \& Yip, S. K. (2005). The impact of urinary incontinence on quality of life among women in Hong Kong. Hong Kong Med J, 11, 158-163.

Riss, P., \& Kargl, J. (2011). Quality of life and urinary incontinence in women. Maturitas, 68, 137-142. http://dx.doi.org/10.1016/j.maturitas.2010.11.006

Senra, C., \& Pereira, Mg. (2015). Quality of life in women with urinary incontenance. Rev Assoc Med Bras, 61(2), 178-83.

Son, Y. J., \& Kwon, B. (2010). Predictive risk factors for impaired quality of life in middle-aged women with urinary incontinenceInt. Neurourol J, 14(4), 250-5. http://dx.doi.org/10.5213/inj.2010.14.4.250

Tozun, M., Ayranci, U., \& Unsal, A. (2009). Prevalence of urinary incontinence among women and its impact on quality of life in a semirural area of Western Turkey. Gynecol Obstet Invest, 67, 241-249. http://dx.doi.org/ $10.1159 / 000209310$

\section{Copyrights}

Copyright for this article is retained by the author(s), with first publication rights granted to the journal.

This is an open-access article distributed under the terms and conditions of the Creative Commons Attribution license (http://creativecommons.org/licenses/by/3.0/). 